\title{
A Case Report and Review: Be Aware to Avoid Accidents at Home
}

\section{Wedad H. Al-Dahhan1, Zeyad Fadhil2, Muna Bufaroosha ${ }^{3}$, Salam Mohammed ${ }^{4}$, Ali Abd Ali ${ }^{1}$, Emad Yousif ${ }^{1}$}

${ }^{1}$ Department of Chemistry, College of Science, Al-Nahrain University, Baghdad, Iraq

${ }^{2}$ College of Pharmacy, Thi-Qar University, Dhi Qar, Iraq

${ }^{3}$ Department of Chemistry, College of Science, UAE University, Al-Ain, UAE

${ }^{4}$ Department of Chemical and Petrochemical Engineering, College of Engineering and Architecture, University of Nizwa, Nizwa, Oman

Email: dahan6262@gmail.com, emad_yousif@hotmail.com

How to cite this paper: Al-Dahhan, W.H., Fadhil, Z., Bufaroosha, M., Mohammed, S., Ali, A.A. and Yousif, E. (2020) A Case Report and Review: Be Aware to Avoid Accidents at Home. Open Journal of Safety Science and Technology, 10, 33-41. https://doi.org/10.4236/ojsst.2020.102003

Received: March 12, 2020

Accepted: May 8, 2020

Published: May 11, 2020

Copyright $\odot 2020$ by author(s) and Scientific Research Publishing Inc. This work is licensed under the Creative Commons Attribution International License (CC BY 4.0).

http://creativecommons.org/licenses/by/4.0/

\begin{abstract}
The occurrence of accidents can be only being restricted to workplaces as they can occur at homes. Therefore, people should be aware of potential risks at home so that accidents can be avoided. This article deeply touches some of the realistic home accidents by explaining and analyzing them to be as beacon for others to avoid their occurrence. This has a paramount importance to alert people to be careful and take proper actions to avoid accidents. In this research, we discussed the issue of flammable gases, their severity and the need for careful handling of them, especially in hot climates, in addition to the fire hazards resulting from them. And due to the importance of accidents resulting from high electrical loads and fires that can happen as a result of this, this topic was covered by reviewing household accidents resulting from poor wiring, additional loads and poor connections.
\end{abstract}

\section{Keywords}

LPG, Volatile Liquids, Fire Retardants, Electrical Fires, Home Accidents

\section{Introduction}

Domestic accident is an accident that takes place at home or in its immediate surroundings [1]. Contrary to common opinion, home is one of the most dangerous places in which to be. Some of the accidents that occur here result in more deaths and serious injuries than on streets, highways and schools. Backing this assertion, in the US about 27,000 to 30,000 people die in home accidents 
annually, while over 4,000,000 are disabled and the cost including wage loss, medical expense and insurance runs to 800,000,000 [2].

Though more comfort now exists in the modern world, some dangers accompany this optimal condition which we must live with. For instance, shocks, burns, falls and violent deaths can only stop if a stop is put to the use of electrical appliances in the homes and a ban placed on the use of gas and other forms of modern fuel for domestic purposes. Since this sophistication now pervades our environment, we must live with it, practice it and teach it. To remove everything in which there is an element of danger from our homes and lives will be to stop living [3].

The World Health Organization (WHO) has indicated that about $95 \%$ of the injuries resulting in death take place in countries with low or moderate income levels and those injuries are responsible for about $40 \%$ of the child and adolescent deaths in these countries [4]. It is also reported that falls, burns and poisoning most of which occur in the home account for approximately $25 \%$ of all the injuries in the world [5]. The World Health Organization also reported that every day around the world the lives of more than 2000 families are torn apart by the loss of a child to an unintentional injury or so-called "accident" that could have been prevented [6].

Smart home is a complex system that controls various processes in a house, namely: climate, lighting, security and others. Its functions also include ensuring the home safety and security. The smart home should be able to detect dangerous situations, conflicts and hazardous situations, as well as to contribute building protection [7]. The importance of the study highlights that it touched on real things that took place in homes, and therefore it is necessary to warn through this study to take care and caution to prevent it from happening in other places.

\section{Methodology}

In this article some of the most common household accidents are supported by realistic examples from our daily lives related to cooking gas handling, general fires and electric fires. The research data was collected based on realistic incidents that the researcher benefited from and used it to educate others and guide them on the nature of the risks mentioned in the research.

\section{Liquefied Petroleum Gas (LPG)}

Liquefied petroleum gas (LPG) is a commercial type of fuel composed of propane and butane [8]. LPG vapor is odorless, colorless, and heavier than air, so it does not disperse easily without wind or ventilation [9]. Ethyl Mercaptan is added to LPG for the smell so that any leakage can be easily identified [10]. LPG is flammable and heavier than air so that it will settle and may accumulate in low spots such drains and basements. Here it could present a fire or explosion or suffocation hazard [11].

Cooking gas (LPG) is used a lot in homes and in places where gas is not available through flexible poly vinyl chloride pipelines, gas cylinders are used for this purpose. Some people think that putting the gas cylinder out of the house would 
be safer. This belief is somewhat true, but in other cases, putting the cylinder attached to the cook out of the house will lose the sense of the smell of the gas leaking out of the cylinder if it happens. The case reported below is an example of fire accident got into one of the houses after the gas leaked from the cylinder placed outside the house in a place that can be said to be semi-closed (see Figure 1). Because the gas is heavier than the air, after the leak, it builds up at the bottom. No one at home was feeling the smell of gas because the cylinder was outside the house, but when the door opened to the space where cylinder was located; there was an explosion in the accumulated gas which ignited from cook flame as shown in Figure 2.

\section{Don't Put Volatile Liquids inside Your Car}

In hot and sunny countries, cars are exposed to sunlight, which can accumulate heat inside the car with a higher temperature than outside because of the so-called greenhouse phenomenon. Therefore, it is not advisable to put perfumers, air freshener and gas liters inside the car because it will be exposed to an explosion, and this is what happened to the gas lighter placed inside a car, which led to its explosion (see Figure 3). An air freshener has caused a car to explode in a car park which led to injuring one person. The explosion occurred after an accumulation of gases from the fresheners which were accidently ignited by a cigarette as shown in Figure 4 [12].

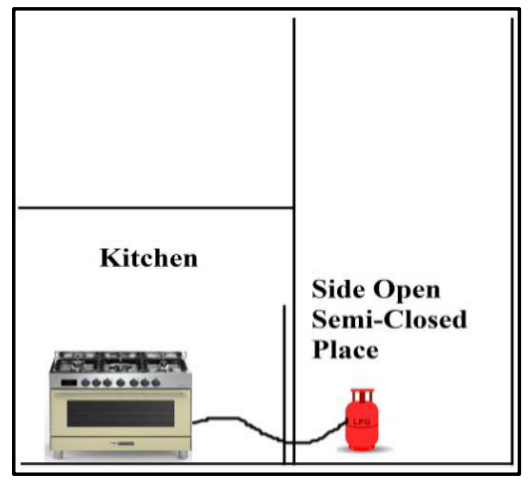

Figure 1. The location of stove and LPG cylinder.

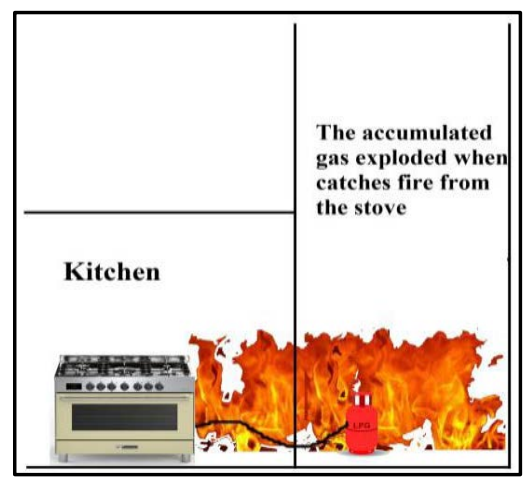

Figure 2. The accumulated gas exploded. 


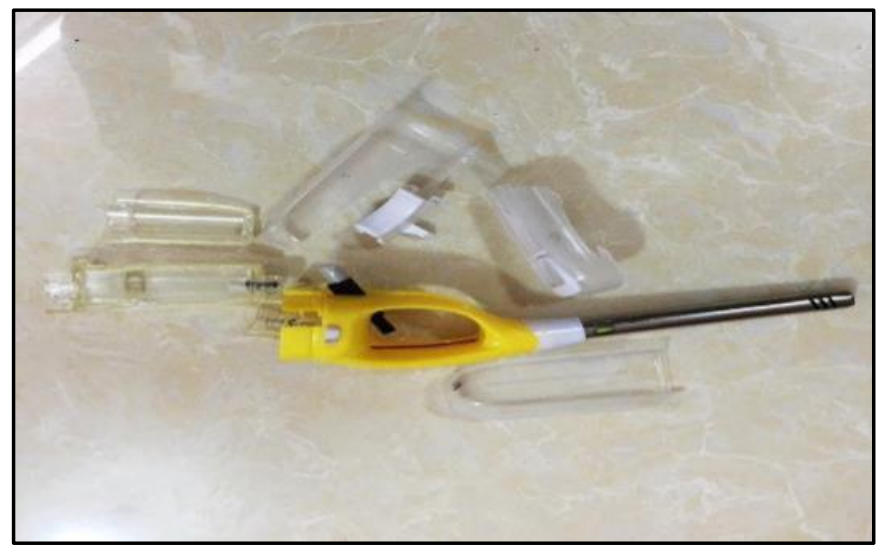

Figure 3. Gas lighter exploded.

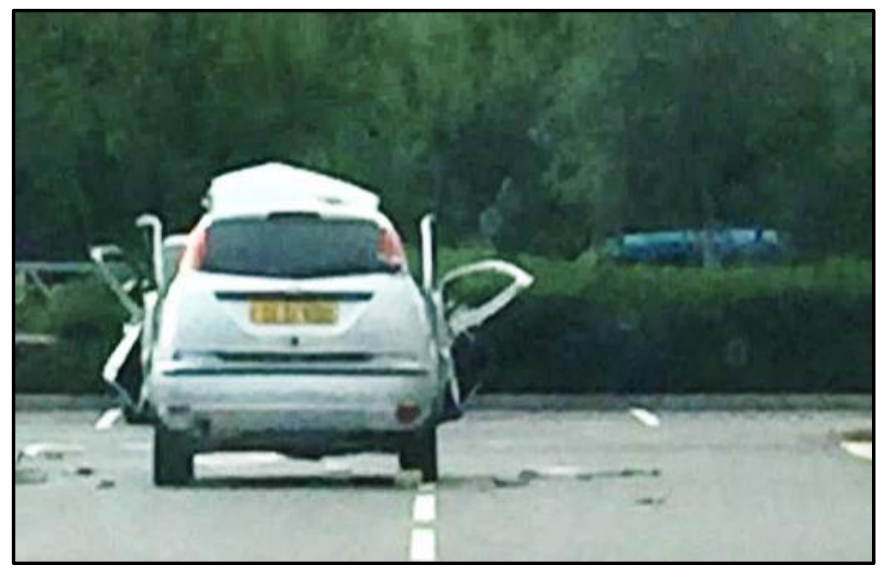

Figure 4. Air freshener causes car to explode in a car park in Southend.

\section{Fire Retardants}

Polymers are commonly used in many applications, such as electrical and electronic equipment, textiles and furniture, cars, trains, ships and aircrafts as well as construction products. Because polymers are combustible, special care must always be taken for their fire-safety.

Efforts have been devoted to discover ways to prohibit ignition, flame spread, heat production as well as harmful and toxic materials evolution. Depending on the polymer, the product type and the end use application, many different fire-retardant methods can be used. Fire retardants can be used to influence the different phases of the combustion process [13]. Most plastic materials get combusted upon exposure to fires. These combustions vary in their degree of flammability and the amount of toxic fumes they release [14]. The presence of fire-retardant materials in a child's toy that was put on the top of heater was melted, but it did not burn. The question here is that what will happen if the toy was made of plastic without fire-retardant? Figure 5 illustrates a reckless monitoring of children in a place where dangerous materials and naked flames are present. The toy did not burn because it was made of plastic with fire-retardant as shown in Figure 6. 


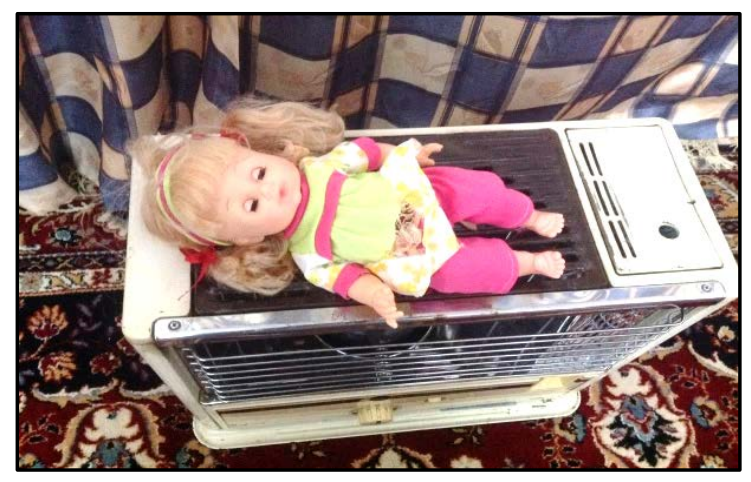

Figure 5. Baby put a toy on kerosene heater.

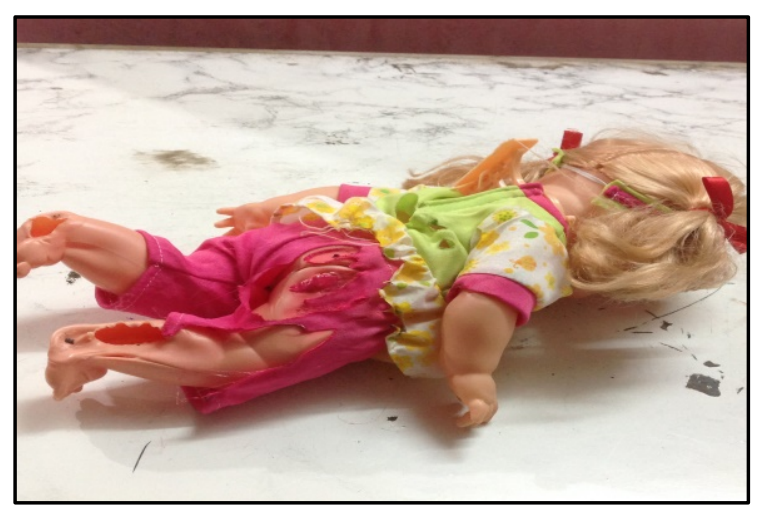

Figure 6. Plastic of the toy melt but did not burn.

\section{Candle and Perfume Bottle}

A flammable liquid is a liquid with a flashpoint below $37.8^{\circ} \mathrm{C}$ [15]. Flash point is the lowest temperature at which a liquid can gives off vapor to form an ignitable mixture in air near the surface of the liquid. The lower the flash point, the easier it is to ignite the material [16]. Alcohol is used in many perfumes formulations. It assists the ease addition and blending of essential oils and fragrances to produce a sustainably clear perfume solution. Denatured ethanol is usually the alcohol used as the main carrier for the fragrance oils. Ethanol evaporates rapidly as it touches a body skin and consequently distributing fragrances evenly over the skin surface [17]. One can commit mistakes at home if dealing with dangerous materials such as perfumes as a consequence of their ignorance of safety measures. The situation we are going to address is realistic and led to burning of a house. In some countries, there are some power shortages which lead to constant power cut. This cut leads people to use lighting alternatives such as candles. The situation we are dealing with is a fire that occurred because of placing a candle on top of a fridge. Some paper sheets were underneath that candle and a perfume bottle was in the vicinity as shown in Figure 7. Leaving the candle unattended signifies serious consequences and the possibility of a fire. This is what happened when the candle fell and burned papers underneath, and then the adjacent perfume bottle caught fire. The top of the fridge and its door was completely burned as shown in Figure 8. 


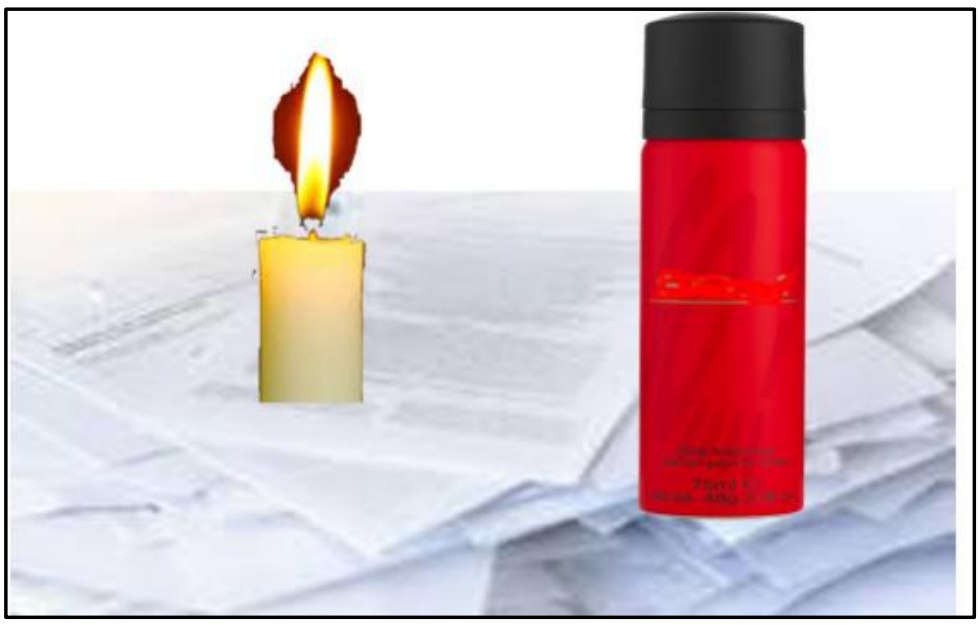

Figure 7. Papers and perfume bottle.

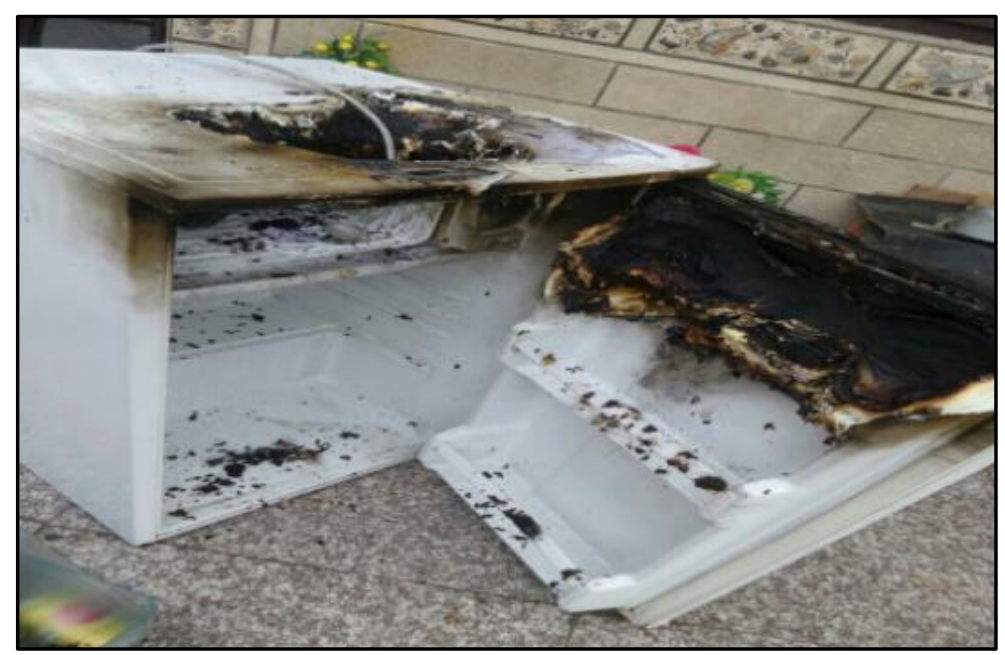

Figure 8. The burned refrigerator.

\section{Electrical Fires}

Electrical fires are common in both commercial and residential settings. According to data from Electrical Safety Foundation International, more than $(50,000)$ home electrical fires occur annually with nearly (500) deaths and over (1400) injuries. The property damage for residential is over ( $\$ 1$ billion). On the commercial side, according to the US Fire Administration (8200) fires occurred from electrical malfunction, totaling (\$431 million) in losses in 2017. With electrical fires becoming increasingly common, residences and commercial businesses need to take action [18]. Home electrical fires can start in wiring, electrical appliances, and lighting devices, as well as in any equipment powered by electricity such as cooking, heating, and office equipment, as well as electrical distribution or lighting equipment. Figure 9 shows the types of equipment involved in home fires [19]. Researchers have multiple articles reviewing cases and accidents in various and varied sites [20] [21] [22].

Figures 10-12 show some examples of multiple types of electric fires. 


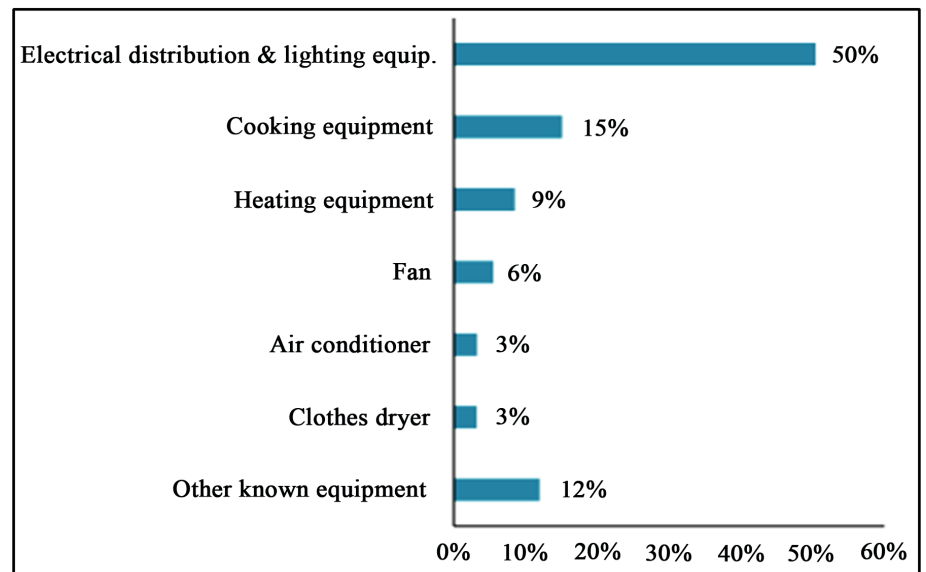

Figure 9. Home fires involving electrical failure or malfunction by equipment involved in ignition (2012-2016).

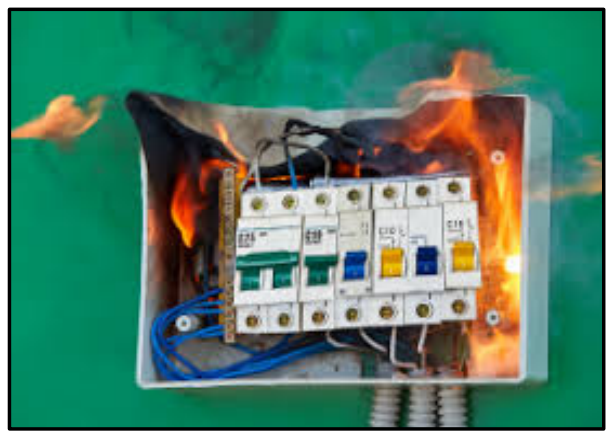

Figure 10. Main board fire.

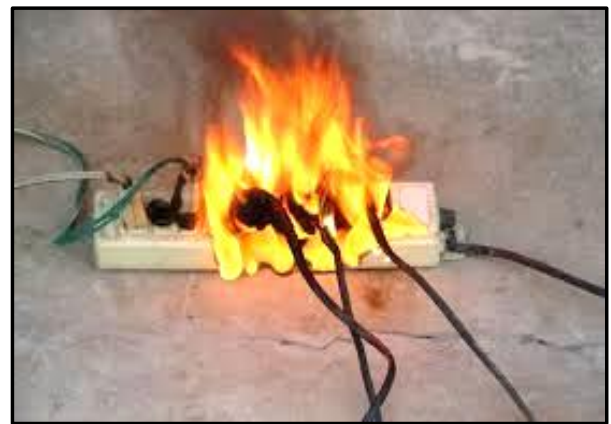

Figure 11. Multiple electricity base catch fire.

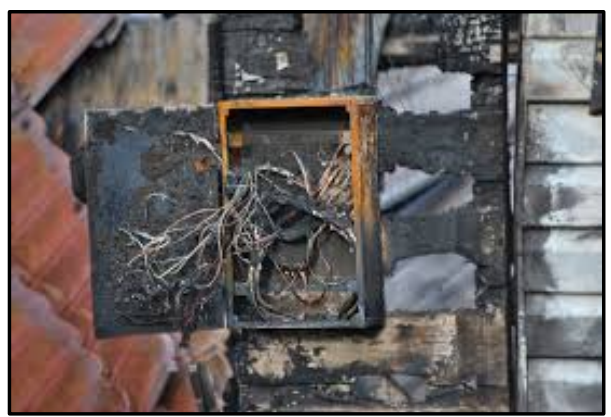

Figure 12. External main board fire. 


\section{Conclusion}

To sum up, houses are considered a dangerous environment if materials and equipment are not handled properly. Most of the incidents reviewed in this article are common and require caution in their causes to avoid their occurrence, while others are uncommon, such as a gas leak, which requires taking into account aspects of caution and caution against them to avoid fires caused by them. The importance of the study highlights that it touched on real things that took place in homes, and therefore it is necessary to warn through this study to take care and caution to prevent it from happening in other places.

\section{Recommendations}

One of the most important recommendations in the topic of gas handling is to place the cylinder in a well-ventilated place and avoid placing it in closed or semi-closed places, taking into account the density of the gas compared to the density of the air to know where it is when the leak occurs. Since children are present at home and do not realize the seriousness of things, it requires more care and supervision for them and warns those who are aware of them in one way or another about the seriousness of things. With regard to electricity fires, knowing the main causes of these accidents which can be summarized in (bad electrical wiring, faulty outlets and appliances and improper use of extension cords) enables us to avoid their occurrence.

\section{Acknowledgements}

The authors acknowledge the Al-Nahrain University for their encouragement.

\section{Conflicts of Interest}

The authors declare that they have no conflicts of interest.

\section{References}

[1] Sirohi, et al. (2015) Domestic Accidents: An Emerging Threat to Community. International Journal of Medical Science and Public Health, 4, 1-5. https://doi.org/10.5455/ijmsph.2015.14012015237

[2] Oyerinde, O. (1985) Home Accidents in Nigeria: Effects and Measures for Prevention. Journal of Home Economics, 1, 1-9.

[3] Bolton, W., Foster, J. and Nicollas, J. (1963) Your Health Today and Tomorrow, Health and Physical Fitriess Laid Law Brothers.

[4] World Health Organization (2006-2015) Child and Adolescent Injury Prevention: A WHO Plan of Action.

[5] World Health Organization (2014) Injuries and Violence: The Facts 2014. Geneva.

[6] World Health Organization (2008) World report on Child Injury Prevention. https://www.who.int/violence_injury_prevention/child/injury/world_report/World report.pdf

[7] Teslyuk, V. (2018) Development and Implementation of the Technical Accident Prevention Subsystem for the Smart Home System. International Journal of Intelligent 
Systems and Applications, 10, 1-8. https://doi.org/10.5815/ijisa.2018.01.01

[8] Matar, S. and Hatch, S. (2000) Chemistry of Petrochemical Processes. 2nd Edition, Elsevier, Amsterdam, 31.

[9] Demçirbas, A. (2002) Fuel Properties of Hydrogen, Liquefied Petroleum Gas (LPG), and Compressed Natural Gas (CNG) for Transportation. Energy Sources, 24, 601-610. https://doi.org/10.1080/00908312.2002.11877434

[10] LPG Leak Detector for Home. https://www.supergas.com/lpg-for-Home/lpg-leak-detector

[11] Health and Safety Executive (HSE). https://www.hse.gov.uk/gas/lpg/about.htm

[12] BBC News. https://www.bbc.com/news/uk-england-essex-41179132

[13] Esko, M. (2000) Fire Retardants and Product Behavior in Fire Tests. Polymer International, 49, 1222-1225. https://doi.org/10.1002/1097-0126(200010)49:10<1222::AID-PI530>3.0.CO;2-5

[14] Ku, P.L. (1989) Fire Retardants for Readily Combustible Cellular Polystyrene. Advances in Polymer Technology, 9, 57-67.

[15] Wallace, W. (2016) Flammable and Combustible Liquids: Storage and Handling (Rev 9-2013). Workplace Safety, Inc. http://www.workplace-safety-nc.com/articles/Flammable-comb-liquids.html

[16] (2020) The MSDS Hyper Glossary: Flash Point. http://www.ilpi.com/msds/ref/flashpoint.html

[17] Mistral Industrial Chemicals. https://mistralni.co.uk/blogs/articles/15956104-what-is-perfumers-alcohol-and-how -is-it-used

[18] Fire Trace International. https://www.firetrace.com/fire-protection-blog/how-does-an-electrical-fire-start

[19] Campbell, R. (2019) Home Electrical Fires, NFPA Research.

[20] Al-Dahhan, W. and Yousif, E. (2018) Hydrogen Balloons: Bright Colors But Hidden Fire Hazard. International Journal of Public Health \& Safety, 3, 151.

[21] Al-Dahhan, W., Al-Zuhairi, A., Yousif, E., Rasool, H. and Hussein, F. (2017) Bad Filling Ionic Liquid Sample in Split Tube Furnace. Interdisciplinary Journal of Chemistry, 2, 1-3. https://doi.org/10.15761/IJC.1000118

[22] Al-Dahhan, W., Ali, A., Jasim, A., Hussein, F. and Yousif, E. (2017) Evaluating a Chemical/Biological Laboratory to Promote Safety Measures. Oriental Journal of Physical Sciences, 2, 95-102. https://doi.org/10.13005/OJPS02.02.08 